\title{
Working from Home: Impact on Wellbeing and Work-Life Balance
}

\author{
ROYA GORJIFARD* and JOANNE CRAWFORD**
}

\begin{abstract}
Working from home (WFH), teleworking, or telecommuting has become a new work norm since the Covid-19 pandemic. Many organisations are showing an interest in testing a hybrid work style when the pandemic is over; a mix of WFH with office-based work has the potential to improve work-life balance (WLB). Organisations across the globe quickly adopted WFH to maintain their business continuity during the pandemic. However, it co-concurred with particular occupational health and safety (OHS) concerns. Our research review shows that the frequency of WFH is significantly related to its impact on WLB. Women, specifically, are more likely to find it challenging to maintain balance between office work and domestic responsibilities. Additionally, WFH leads to personal costs for many, for example, maintaining a suitable workstation setup at home. The continuous demand for up-skilling/re-skilling due to fast improving technology and job satisfaction is another example of the risk to workers' wellbeing.
\end{abstract}

This research paper reviews the most important risk determinants of WLB due to WFH. We discuss that workplaces should align their strategies in the longer term to support employees' wellbeing risk management. Employers, employees - women particularly - should use this rapid change as an opportunity to learn and grow.

Keywords: Working from home, WFH, Teleworking, Telecommuting, Work-life balance, WLB, work-life balance determinants, Hybrid work model, Wellbeing, Job satisfaction, Upskilling, Re-skilling.

\section{Introduction}

Working from home (WFH) or teleworking has become a new work norm since and during the Covid-19 pandemic. As soon as the World Health Organization (WHO) announced the global pandemic in March 2020 (WHO, 2020), it became clear that businesses could not perform as usual. Working from home helped with business continuity globally. Essential industries, such as logistics, were able to maintain some roles at home while organising business tasks remotely. Despite the early chaos, WFH was found to be a unique way to sustain business continuity and prevent the spreading of Covid-19. This meant a larger proportion of employees started WFH full-time. In New Zealand during the Levels 3 and 4 lockdowns, 27-31 per cent of the total

\footnotetext{
* PhD Candidate, School of Health, Victoria University of Wellington, ProfNZISM, HASANZ registered.

Contact email: roya.gorjifard@vuw.ac.nz

** PhD, Professor, WorkSafe New Zealand Chair in Health and Safety, School of Health, Victoria University of Wellington.
} 
workforce was performing WFH full-time. Several organisations have declared their intention to continue hybrid work models even after the pandemic (Wang et al., 2020).

Some researchers argue that WFH in business as usual (BAU) is different from WFH during crises (Green et al., 2020). For example, a study on the post-Christchurch earthquake disaster confirmed businesses remained sustainable via WFH despite facing critical challenges. WFH management showed a significant dependency on personalised tasks and individual autonomy under the uncertainty of having little control over the chaotic surroundings. Line managers had an important role in connecting individuals and organisations to form organisational outcomes. The authors suggested that organisations should plan and be prepared for the WFH process as part of resilience management (Donnelly et al., 2015).

\section{Terms used}

The Home Work Recommendation 1996, adopted by the International Labour Organization (ILO), defines Home Work as work that is done outside the employer premises either at an employee's home or their other choice of a place that produces a service or product for the employer and results in remuneration (ILO, 1996). Apart from WFH, there are other terms such as teleworking and telecommuting. Teleworking specifically refers to work from home or other places using Information Technology (IT). Telecommuters usually work from home to reduce commuting, which alleviates heavy traffic and lessens the environmental impacts (BelzuneguiEraso et al., 2020; Gus et al., 2003). However, in this article we assume that WFH, teleworking and telecommuting are identical because of the impact of the work on workers' wellbeing and WLB.

In this article, we do not apply the above terms to those who work remotely because of the nature of their jobs such as drivers, distributers, and so on.

\section{Research Question}

We were curious to explain the impact of WFH on employees' health and wellbeing and accordingly to their WLB. Thus, our research question was:

- What are the risk determinants of WFH on employees' WLB?

To come up with a better idea and understanding, we first explored more around the concept of WLB.

\section{The Definition of the Work-Life Balance}

There are several definitions and approaches around the meaning of work-life balance (WLB). Here we reference some relevant definitions.

"WLB as satisfaction and good functioning at work and home with a minimum of role conflict" (Greenhaus et al., 2006).

"WLB as the relationship between the institutional and cultural times and spaces of work and non-work in societies where income is predominantly generated and distributed through labour market" (Felstead et al., 2003, p.53).

"WLB is about being able to combine family commitments, leisure and work - including both paid and unpaid work" (OECD, 2020). 
Work-life balance has been the topic of interest of many scholarly articles in recent years. (Guest, 2002) gathered five theoretical approaches towards WLB as below:

\section{- Segmentation model}

Assumes work and non-work are separate with no interaction between them.

- Spillover model

Assumes that the impact of one area on the other, either positively or negatively, is inevitable.

\section{- Compensation model}

Suggests that dissatisfaction in one area, such as work, could be replaced by an activity in another area. For instance, a person with lots of time because of an undemanding job takes responsibility in a voluntary or community role which is satisfying.

- Instrumental model

Emphasises what is happening in one area as enablers to another area. For example, working overtime to enhance income for a specific personal/family purpose.

- Conflict model

Focuses on difficult circumstances that people might face due to highly demanding areas of life and work.

The Conflict Model has been widely researched. Many other researchers have focused on the Spillover and Compensation models as well. What attracted us was to specify the determinants of WLB independent of the theoretical models. We studied a great number of papers that had qualitative, quantitative or mixed-methods approach on WLB or work-life conflict. Qualitative studies provide a comprehensive method to integrate a framework of the key issues of WLB. On the other hand, quantitative research evaluates the importance of those key variables (Beigi et al., 2018). Quantitative or mixed-method studies gain meaningful understanding of variables and examine their impact by measuring them (Hayes, 2018). This way we tried to achieve comprehensive findings.

In this study, we were not intending to research the psychology and sociology of WLB. We were seeking to explore the most significant determinants of WLB. We found some key components associated with the nature of the influence. For instance, where an individual is struggling to manage a balance between work tasks and family or personal tasks, their type of personality or generation league matters. The pressure of workload for a Type A personality may measure differently for a Type B or a workaholic (Delecta, 2011). In the generation categorisation, Generation X desire more WLB than their Baby Boomer predecessors (Taylor, 2018). It is evident that individuals may perceive the workload and straddle between work and life differently.

On the other hand, whereas the overlap between work and family responsibilities can result in work-family conflict, an employer may have a different perspective. The role of organisations in creating an enabling environment for their employees to stay focused on their job tasks is significant.

Our findings of the most important determinants of WLB are demonstrated in Table 1. 
Table1- Work-Life Balance Determinants (findings of this research)

\begin{tabular}{|c|c|c|c|}
\hline Determinant & Key component & Nature of Influence & Comment \\
\hline Individual & $\begin{array}{l}\text {-Personality Type A, B, workaholic } \\
\text {-Baby boomers, Gen X, Gen Y, Gen } \\
\text { Z }\end{array}$ & $\begin{array}{l}\text { The relationship between workload and the } \\
\text { individual personality type }\end{array}$ & $\begin{array}{l}\text {-The impact of workload on individuals is related to their } \\
\text { expectation due to personality (Delecta, 2011). } \\
\text { - With different generations already in the job market and } \\
\text { their different work attitude and expectations, the nature } \\
\text { of the workload influence could be different from the } \\
\text { classic typical personality definition (Taylor, 2018). }\end{array}$ \\
\hline Family & Family expectation & $\begin{array}{l}\text { The amount of workload and time spent at } \\
\text { work may have a different effect on the } \\
\text { different family situation }\end{array}$ & $\begin{array}{l}\text {-The impact of workload and time spent at work could } \\
\text { depend on the person's role in the family, the family's } \\
\text { expectations on that person, as well as the support the } \\
\text { family provides to that member (Delecta, 2011). } \\
\text {-Employees with the duty of family care (mostly women) } \\
\text { require different work arrangements, such as taking time } \\
\text { off at short notice to manage urgent family matters } \\
\text { (Eurofound, 2021). }\end{array}$ \\
\hline Organisation & $\begin{array}{l}\text { Organisational culture } \\
\text { Organisational support } \\
\text { Managerial support }\end{array}$ & $\begin{array}{l}\text { The relationship between organisational } \\
\text { cultural context and managerial support with } \\
\text { work-life balance }\end{array}$ & $\begin{array}{l}\text {-Ideal organisational cultural context can ease or cause } \\
\text { unease in work-life balance. An ideal work culture } \\
\text { demands perfect performance from employees, which } \\
\text { may interfere with family responsibilities (Van der Lippe } \\
\text { et al., 2018) } \\
\text {-The result of a meta-analysis showed that organisational } \\
\text { support, such as flexible work arrangements, has a } \\
\text { significant role in decreasing work-life conflict (Beigi et } \\
\text { al., 2018). }\end{array}$ \\
\hline Social culture & Extended social responsibility & $\begin{array}{l}\text { Social responsibilities can interfere with } \\
\text { work-life balance }\end{array}$ & $\begin{array}{l}\text { - For example, the collectivist cultural context expects } \\
\text { individuals to have certain responsibilities towards } \\
\text { certain social groups, and at certain times which may } \\
\text { have implications on personal work-life balance } \\
\text { (Delecta, 2011). }\end{array}$ \\
\hline
\end{tabular}




\section{Working from Home at Business as Usual}

Most research before the pandemic aimed to find practical solutions for the organisations' human resources (HR) to facilitate more work-life initiatives within their organisations. More managerial support plans or allowances that assist employees to better organise their family responsibilities have been reported during BAU. Such solutions will also benefit an organisation in achieving productivity and advantage in the market (Lockwood, 2003).

Many organisations reportedly practised several types of flexible work programmes, such as teleworking, flexible time and part-time schedules. (Beigi et al., 2018) referenced a report from the World at Work that mentioned, by 2015,80 per cent of organisations internationally had offered some type of work flexibility to their employees.

The impact of lack of WLB or work-life imbalance manifests as stress in individual behaviour either at work or outside of work. This may result in conflict with colleagues or family. Correspondently, stress may cause underperformance of job tasks, dissatisfaction with work or life, poor health behaviours to try to cope with the consequences, such as using drug and alcohol. The overall impact of work-life imbalance could appear to have behavioural, personal, family and organisational implications (Delecta, 2011).

\section{Forced Working from Home during the Pandemic}

With the announcement of the global Covid-19 pandemic in March 2020, numerous organisations were forced to shift to WFH to ensure their business continuity. Working from home also assisted in the ability for organisations to function safely and to reduce the spread of Covid-19. While the results of pre-pandemic research indicated positive performance and organisational productivity of WFH (Martin et al., 2012), lower work-family conflict and higher job satisfaction (Gajendran et al., 2006), they did not test forced WFH. Forced WFH due to the pandemic possibly resulted in slightly different outcomes. For instance, lack of proper equipment and technology, inaccessibility to a high-speed internet connection, inappropriate office space at home locations and interference of parental responsibilities with work, such as homeschooling, were among the issues reported by many workers for WFH, especially in the first days or weeks of the pandemic. Positive outcomes of WFH, such as worker retention and reduced levels of turnover, would not apply in short-term forced WFH situations.

The forced WFH situations did not happen in a continuous work style for businesses either. As community transmission differed in many communities across the globe, the emergency lockdown resulted in a variety of rules and restrictions. Accordingly, businesses switched between sometimes working at their work premises and sometimes WFH and some continue to do so in Auckland and other places. This inconsistency is unlikely to allow a reliable measurement of organisational outcome and productivity. It may have intensified stress and affected workers' wellbeing as well as burdening organisations. There is currently limited research examining and reporting such multiple and sudden switching between workstyles.

Donnelly et al. (2015) researched WFH in the aftermath of a natural disaster, drawing on the experiences of managers and workers after a series of earthquakes in Christchurch New Zealand between September 2010 and January 2012, and found out that changing from WFH to BAU significantly affected employees' wellbeing and engagement. They also demonstrated 
that forced WFH posed risks of increased work-family conflict and domestic violence as well as financial stressors, such as remuneration cuts and leave entitlements while return to normal work had implications for wellbeing. Therefore, the research suggests that the transition between home and work should happen gradually.

A second study post-Christchurch disaster showed that some workforces were still interested in WFH, while a fewer number of managers supported it (Green et al., 2017). Research conducted during the current Covid-19 pandemic showed that 90 per cent of New Zealanders were still interested in WFH after the pandemic (Green et al., 2020).

Despite previous reports related to the benefits of WFH on productivity and business continuity in various studies since the mid-1990s, we have not seen any record that WFH has been suggested as a method of business continuity in the organisations' crisis preparedness plan. Therefore, some organisations and their employees were not prepared or trained to use digital technology and tools. The pressure of performing work tasks without proper planning and skills caused stress (O'Bannon, 2020). This prolonged stress, with the combined effect of family responsibilities and care, for example homeschooling, and other domestic tasks, could threaten the wellbeing and mental health of individuals. It is more likely that women employees, as the traditionally first family care providers, were affected more. One thing that is less mentioned in the literature is elder care. There are many workers who have an older parent or relative at home who needs support. Working from home is a multisided flexibility tool. Caregiver employees will benefit from WFH, but if their care receivers, such as children or elders need more attention or physical care, it may be disruptive to their work task (Gálvez et al., 2020).

The frequency of WFH significantly impacts on work-family balance (Green et al., 2020), with a reliable pre-pandemic meta-analysis showing that WFH increases job satisfaction and productivity and alleviates work-family conflict. However, the research reveals that positive outcomes of WFH on work-family balance could be reversed if it continues more than two or three days per week. The point when the relationship between the amount of WFH and workfamily balance starts reverse effecting remains vague. Social supports have been mentioned as a moderator between those variables.

The authors did a great deal of research around WFH in New Zealand as well. They referred to Stats NZ (2019a), which shows that one-third of New Zealand employees had experienced WFH in their main job in different capacities and forms, with 27-31 per cent of New Zealand employees working full-time from home during the Covid-19 alerts Levels 3 and 4 in 2020. According to (Green et al., 2020), support can act as a moderator to reduce the ambiguity of the relationship between WFH and WLB. Organisational, managerial, social, and individual support are the types mentioned in the study. This corroborates with our findings of the different categories of WLB presented in Table 1.

\section{Overall Findings around Working from Home}

Several articles illustrated that WFH leads to personal costs for many workers who do not necessarily have an office set-up or a separate office room, proper technology items, such as computer or laptop, and are not connected to a strong and stable internet network.

Although early studies before the pandemic indicated WFH could noticeably reduce the financial costs of and for the businesses (Kaur et al., 2020), some earlier research demonstrated 
that flexibility due to technology was a significant point of interest for employees (Crosbie et al., 2004). Meanwhile, increased reluctance towards WFH has been through reasons, such as occupational stress, health, and fitness issues, in addition to challenges to maintain the boundaries between work and household duties.

Maintaining the boundaries between work tasks and household responsibilities has also been researched. Work and home as totally separated places arose after the first and second industrial revolutions are now merging again due to the fourth industrial revolution (Crosbie et al., 2004). This merging has been accelerated thanks to the Covid-19 pandemic which reinforced digital transformation.

As mentioned earlier, women are more likely to feel the hit of the pandemic because of their traditional role as primary caregivers (Reilly, 2012). An evidence-based descriptive study in Australia examined the role of gender on WFH. The findings of their experiment proved that women may take advantage of WFH in a shorter period in terms of having a sense of control over their double paid and unpaid duties. But in the longer term, WFH reinforces the gender gap inside and outside the home (Powell et al., 2015). Another study also evidenced that the enhanced stress level due to mixing work and home environments may degrade the advantages of WFH with regards to WLB (Beauregard et al., 2019).

Similarly, Crosbie et al. (2004) examined the relationship between WFH and gender in a focus group with 70 per cent female workers. The result showed that workers' skill set, income, discretion level, and gender were significant to their experience regarding WFH. The research conducted on the general WFH concept, and not specifically to teleworking and technology only. The results resonate with other research findings such as (Williams, 2001), which determined the importance of personal, care and work concerning two dimensions: time and space. When it came to mixed personal time and space, women, as the traditional caregivers, were affected the most, while men experienced fewer problems as the traditional income earners (Van der Lippe et al., 2018).

In terms of care, the flexibility to balance various work and household responsibilities made WFH seem comforting, except that worktime, then, was not separated. While those who allocated a separate space for work were able to better focus on work, the research result, nonetheless, found a blurring with regards to WLB. The main issues found by the literature were working longer hours for lower pay an)d the inability to switch-off (Felstead et al., 2017). Bouziri et al. (2020 mentioned that overlaping boundaries between home and work time instigated psychological risk.

Choosing the right technology and tools that are fit for purpose can reduce the technical implications. Teleworking can trigger social and professional isolation. Virtual teamwork and engagement are essential to sustain workflow and productivity (Crawford et al., 2011). An appropriate workstation can reduce the risk of musculoskeletal issues due to poor ergonomic set-up (Bouziri et al., 2020). Simultaneously, workers need to switch off at certain times and not over work. Continuous work without switching off caused fatigue and musculoskeletal issues (Tamers et al., 2020). MSD cited as a common health issue in working places (Crawford et al., 2020).

Fast-changing circumstances of the twentieth century in social, economic, and technical aspects have brought up different generations. Generational diversity in the workplace is an important issue that has been a topic of numerous articles. By now, a good proportion of 
Generation Z (1996-2012) has already entered the workforce while Baby Boomers (19461964) are still occupying a proportion of workforces. Organisations who are committed to diversity should see generational diversity as a component of organisational diversity (Wood, 2005). Organisational planning and, accordingly, wellbeing and WLB plans should be openminded and cannot be biased by generational tensions. Employees are individuals who could never completely fit a generational stereotype or otherwise (Taylor, 2018).

The gender gap is considerable in the way men and women experience work according to an (OECD, 2020) report. Average employability rate recorded 83 per cent and 70 per cent for men and women, respectively, while men's earning was 13 per cent higher. Men work more hours per week ( $\sim 50 /$ week) than women, and women spend much more time on unpaid work, therefore, being more occupied in the sense of both paid and unpaid work. Men spend 90 minutes per day more on paid work while women spend about 2 hours more per day on unpaid work than men.

In the current pandemic, men and women were impacted differently. An analysis published by the Office of National Statistics UK (ONS, 2021) indicates that, between March 2020 and January 2021, men had an increased mortality rate (>18 per cent) due to Covid-19, while more women's wellbeing was impacted. Women experienced a higher layoff rate of 6.9 per cent in July 2020. The rate had some rise and fall until it reached almost equal to men's layoff rate by the end of 2020. The analysis also showed that women carried out unpaid household duties and childcare more significantly when WFH. Unemployment figures from StatsNZ (2021) peaked in September 2020 at 5.3 per cent for women and 4.7 per cent for men., accordingly 4.8 and 5.8 per cent unemployment for men and women.

In general, women face more challenges in male-dominant work environments to prove their competency and credibility, and the WFH situation is challenging in terms of separating the work-home responsibilities. Interviews with several female professionals echoes that they managed to be well-organised and self-disciplined to harmonise their professional work and life in a good balance (Gorjifard, 2020).

\section{Approach to Hybrid Work Style Post-Pandemic}

Many pieces of literature forecast that several types of job roles will continue with a combination of office and teleworking known as a hybrid work model post-pandemic (Wang et al., 2020). This hybrid work model may come to reality in different forms and capacities. Highly educated and well-paid workers, who occupy a minority of the job market, are more likely to persist in hybrid work styles. Several elements, such as organisational goals, productivity, premise and asset cost, talent acquisition, and others may influence the organisations' future choice of hybrid combination ratio (Lund et al., 2020).

Since the pandemic has unavoidably impacted every business, future solutions are more likely to be aligned to chasing productivity demands (Ab Wahab et al., 2020). Organisations' strategies should propose more supports to lessen the adverse effect of this increasing demand. They will need a significant plan for employees' health and wellbeing to help to maintain WLB. Achieving wellbeing requires a social exchange between employees and employers. The managerial role, team management and team environment, policies and strategies remain crucial. 
The future of work, indeed, has been changing since the widespread of information technology. This transformation has accelerated through the current pandemic. In the job market, many jobs may vanish, and numerous others will be created due to new technology, such as automation and artificial intelligence. Because of the change, demands on new skills matching the modern workplaces will grow. According to a published report from 10 developed countries, 40 million to 160 million people will face job transition by 2030 . Their jobs will be altered or will totally change (Lund et al., 2020). The skill shift is beyond the WFH and hybrid work form. Adaptation to skills replacement needs prior planning, preparation, and training. Without a proper plan and strategy, workforces will suffer intense job insecurity and unemployment. Awareness and strategising for longer-term reskilling-upskilling is key to keeping the workforce competent and confident enough for the future of work (Madgavkar et al., 2019)

\section{New Zealand Context}

According to (StatsNZ, 2019a): "Work-life balance refers to effectively managing professional and personal activities - paid work and the other activities people find important outside of work." With the latest survey in 2018, three-quarters of the New Zealand workforce showed a good WLB and satisfaction with their job (Figure 1). As the graph shows for the younger generation, WLB is strongly associated with job satisfaction. Understandably, for the middleaged workforce, the relationship between the two variables loses strength as other factors may influence the WLB, such as family responsibilities.

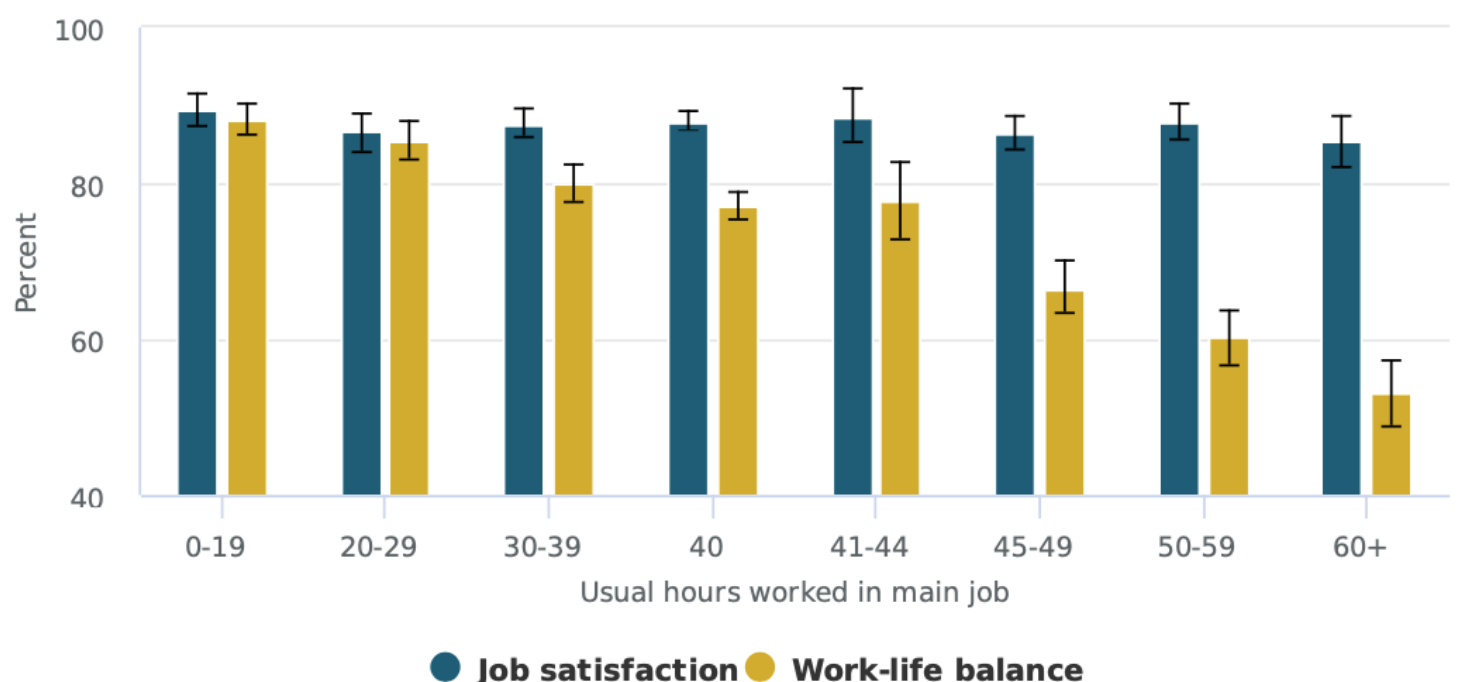

Error bars indicate $95 \%$ confidence interval.

Figure 1- correspondence between job satisfaction and work-life balance (\%) based on usual work hours, 2018 (StatsNZ, 2019b).

The figures for job satisfaction are measured with the following indicators:

- the flexibility of working hours

- job security

- autonomy and level of control

- the overall quality of workplace and workplace relationship 
- work-related tiredness and stress

- having the right skill

- job strain (a concept that StatsNZ (2019b) uses to measure job quality).

It is relevant to mention that employed workers showed higher overall life satisfaction than unemployed. Those employed with no sense of job satisfaction demonstrated lower overall life satisfaction similar to the unemployed.

We conclude that, in the kiwi work cultural context, New Zealanders' job satisfaction is crucial to WLB. It is then significant to underpin the situation with the impact of the pandemic on the job market. There are also large and accelerating changes due to digital transformation and automation with consequences for jobs and changes in skills requirements. Therefore, how do we maintain these levels of job satisfaction, wellbeing and WLB in the wake of the impact of the pandemic, the accelerated job market change, digital transformation, and automation?

\section{Conclusion}

Most of the researchers used the cross-sectional method to study WFH in work samples within a short period. These studies often investigated WFH and its impact on wellbeing and WLB. We demonstrated the findings of our reviews in Table 1. As shown in the table, the determinants of WLB can be culture and context-dependent, as well as individual dependent. The result of a specific work context, a culture, and an area of work may or may not be necessarily reproducible or applicable to another work sample. We clarified the lack of more comprehensive longitudinal studies.

\section{Recommendation for Future Research}

We suggest that a longitudinal study would probably reveal hidden aspects of WFH or a hybrid work model and its impact on wellbeing and WLB. The current pandemic has made this situation more accessible to researchers in this field. It would be relevant to use the current situation as it is happening. Further inclusive research should examine the frequently mentioned issues by earlier studies in the longer run. We highly recommend more focus on the impact on culture, context and gender.

\section{Recommendations to Make the Future of Work more Sustainable}

As mentioned in part 4, the scale of job transformation is significant. The change could be more manageable if it is identified and planned for. There are many factors to consider. Here, we would like to highlight some strategies that would help secure more jobs for more workers and, therefore, to sustain wellbeing and WLB across the community. Our focus is on both the individual and business/organisational levels that are listed in Table 1. We believe these two determinants are fundamental and that they significantly influence family and society as well.

\section{Organisations and Businesses Strategy}

Organisations should have a clear idea of the extent their work design will be changed by new technology. Most work designs will be partially or completely replaced. Partially automatable 
jobs will require new/modified work tasks, and consequently new/modified skills (World Economic Forum, 2021).

Realistically, organisations will plan training for up-skilling in order to retain parts of their workforces in new/modified jobs. But the populations of workers who face job losses will need up-skilling or re-skilling to start new occupational roles. There will be a notable gap in identifying those new skills, skill training analysis, and planning new training courses. Business leaders, policy makers, and educators should analyse and plan new training courses.

Lund et al., (2020) recommends that organisations could take this unique once-in-a-generation opportunity to decrease the attrition rate by providing training/learning programmes that assist workers to skill up for new career pathways.

Our research on several resources noticed the following possible pattern for the change in jobs:

- Automation and digital transformation are not happening as a uniform and similar phenomenon throughout workplaces and job roles.

- Low-income workers and low skill roles are much more likely to be replaced by automation.

- Higher educated/skilled workers are more likely to secure their jobs.

- Degree inflation will result in an upsurge of job postings.

- The shift in the job market and change in the geography of employment and unemployment will happen.

It seems relevant to establish organisations as linking hubs to match and connect workers to upskilling programmes, connect them to new job opportunities, and access businesses to career pools.

\section{Individual Strategy}

Workers should seek ways to expand their competency and skills and be prepared for future work. Continuous learning might be challenging but it is the rule of survival in the future of work when many jobs are at risk of disappearing or altering.

The concept of lifetime learning here comes to reality. An idea that is necessary for reskilling and upskilling (Ellingrud et al., 2020). This can be taken as an opportunity for some to move into more productive and better paying jobs. Lifetime learners use every chance to learn and develop new skills.

There might be radical job alteration (Part 4) that needs decent focus, learning and coping skills. Lifelong learning can help support individuals to be prepared for future possibilities, development of new skills and job searching.

A healthier workforce and healthier workplaces in the future of work is the joint responsibility of individuals, organisations, business leaders, and policy makers to aid in the development of good work for all. 


\section{References}

Ab Wahab, M., \& Tatoglu, E. (2020). Chasing productivity demands, worker well-being, and firm performance: The moderating effects of $H R$ support and flexible work arrangements. Personnel review, 49(9), 1823-1843. https://doi.org/10.1108/PR-01$\underline{2019-0026}$

Beauregard, T. A., Basile, K. A., \& Canonico, E. (2019). Telework: outcomes and facilitators for employees. In R. N. Landers (Ed.). The Cambridge handbook of technology and employee behavior (pp.511-543). Cambridge University Press.

Beigi, M., Shirmohammadi, M., \& Stewart, J. (2018). Flexible Work Arrangements and WorkFamily Conflict: A Metasynthesis of Qualitative Studies Among Academics. Human Resource Development Review, 17(3), 314-336. https://doi.org/10.1177/1534484318787628

Bouziri, H., Smith, D. R. M, Descatha, A., William, D., \& Jean, K. (2020). Working from home in the time of COVID-19: How to best preserve occupational health? Occupational and Environmental Medicine, 77(7), 509-510. http://dx.doi.org/10.1136/oemed-2020$\underline{106599}$

Crawford, J. O., MacCalman, L., \& Jackson, C. A. (2011). The health and well-being of remote and mobile workers. Occupational Medicine, 61(6), 385-394. https://doi.org/10.1093/occmed/kqr071

Crosbie, T., \& Moore, J. (2004). Work-life balance and working from home. Social Policy and Society, 3(3), 223-233. https://doi.org/10.1017/S1474746404001733

Delecta, P. (2011). Work life balance. International Journal of Current Research, 3(4), 186189.

Donnelly, N., \& Proctor-Thomson, S. B. (2015). Disrupted work: home-based teleworking (HbTW) in the aftermath of a natural disaster. New Technology, Work and Employment, 30(1), 47-61. https://doi.org/10.1111/ntwe.12040

Ellingrud, K., Gupta, R., \& Salguero, J. (2020). Building the vital skills for the future of work in operation. McKinsey \& Company. https://www.mckinsey.com/businessfunctions/operations/our-insights/building-the-vital-skills-for-the-future-of-work-inoperations

Eurofound. (2021). Working conditions and sustainable work: An analysis using the job quality framework, Challenges and prospects in the EU series. Publications Office of the European Union, Luxembourg.

Felstead, A., Jewson, N., \& Walters, S. (2003). Managerial control of employees working at home. British Journal of Industrial Relations, 41(2), 241-264.

Gajendran, R. S., \& Harrison, D. A. (2006). The Good, the Bad, and the Unknown About Telecommuting: MetaAnalysis of Psychological Mediators and Individual 
Consequences. Academy of Management Annual Meeting Proceedings, 8(1), D1-D6. https://doi.org/10.5465/ambpp.2006.27161834

Gálvez, A., Tirado, F., \& Martínez, M. J. (2020). Work-life balance, organizations and social sustainability: Analyzing female telework in Spain. Sustainability, 12(9), 3567. https://doi.org/10.3390/su12093567

Gorjifard, R. (2020). Female Health and Safety Professional in the Workplace. New Zealand Institute of Safety Management (NZISM)/Members/Papers, https://adobe.ly/3q2NfVq

Gratton, L. (2021). Four Principles to Ensure Hybrid Work Is Productive Work. MIT Sloan Management Review, 62(2), 11A-16A.

Green, N., Tappin, D., \& Bentley, T. (2017). Exploring the Teleworking Experiences of Organisations in a Post-Disaster Environment. New Zealand Journal of Human Resources Management, 17(1), 1-19.

Green, N., Tappin, D., \& Bentley, T. (2020). Working from home before, during and after the Covid-19 pandemic: implications for workers and organisations. New Zealand Journal of Employment Relations, 45(2), 5-16.

Greenhaus, J. H., \& Powell, G. N. (2006). When Work and Family Are Allies: A Theory of Work-Family Enrichment. The Academy of Management review, 31(1), 72-92. https://doi.org/10.5465/amr.2006.19379625

Guest, D. E. (2002). Perspectives on the study of work-life balance. Social Science Information, 41(2), 255-279.

Harker Martin, B., \& MacDonnell, R. (2012). Is telework effective for organizations? A metaanalysis of empirical research on perceptions of telework and organizational outcomes. Management Research Review, 35(7), 602616. https://doi.org/10.1108/01409171211238820

Hayes, A. F. (2018). Introduction to mediation, moderation, and conditional process analysis: a regression-based approach ( $2^{\text {nd }}$ ed.). The Guilford Press.

ILO. (1996). R184 - Home Work Recommendation, 1996 (No. 184). https://www.ilo.org/dyn/normlex/en/f?p=NORMLEXPUB:12100:0::NO::P12100_IL O_CODE:R184

Kaur, T., \& Sharma, P. (2020). A study on working women and work from home amid coronavirus pandemic. Journal of Xi'an University of Architecture and Technology, XII(V), 1400-1408

Lockwood, N. R. (2003). Work/life balance: Challenges and Solutions. Society of Human Resource Management.

Lund, S., Madgavkar, A., Manyika, J., \& Smith, S. (2020). What's next for remote work: An analysis of 2,000 tasks, 800 jobs, and nine countries. McKinsey \& Company. 
https://www.mckinsey.com/featured-insights/future-of-work/whats-next-for-remotework-an-analysis-of-2000-tasks-800-jobs-and-nine-countries

Madgavkar, A., Manyika, J., Krishana, M., Ellingrud, K., Yell, L., Woetzel, J., Chui, M., Hunt, V., \& Balakrishan. The future of women at work. Transitions in the age of automation. McKinsey Global Institute. https://www.mckinsey.com/ /media/mckinsey/featured\%20insights/gender\%20equali ty/the $\% 20$ future $\% 20$ of $\% 20$ women $\% 20$ at $\% 20$ work $\% 20$ transitions $\% 20$ in $\% 20$ the $\% 20 \mathrm{a}$ ge $\% 20$ of $\% 20$ automation/mgi-the-future-of-women-at-work-full-reportjune\%202019.pdf

Martin, B., \& MacDonnell, R. (2012). Is telework effective for organizations? A meta-analysis of empirical research on perceptions of telework and organizational outcomes. Management Research review, 35(7), 602-616.

O’Bannon, I., M. (2020). Covid-Normal: Worker Stress, Work/Life Balance and Productivity Start to Stabilize. CPA Practice Advisor, 30(5), 32-33.

OECD. (2020). Work-Life Balance. https://www.oecd-ilibrary.org/sites/e6597da1en/index.html?itemId=/content/component/e6597da1-en

ONS. (2021). Coronavirus (COVID-19) and the different effects on men and women in the UK, $\begin{array}{llll}\text { March } & 2020 & \text { to } & \end{array}$ https://www.ons.gov.uk/peoplepopulationandcommunity/healthandsocialcare/conditio nsanddiseases/articles/coronaviruscovid19andthedifferenteffectsonmenandwomeninth eukmarch2020tofebruary2021/2021-03-10

Reilly, A. (2012). Equality and family responsibilities: A critical evaluation of New Zealand law. New Zealand Journal of Employment Relations, 37(1), 161-166.

StatsNZ. (2019a). Most Kiwis find good balance between work and home. https://www.stats.govt.nz/news/most-kiwis-find-good-balance-between-work-andhome

StatsNZ. (2019b). Job Satisfaction and wellbeing. https://www.stats.govt.nz/reports/jobsatisfaction-and-wellbeing

StatsNZ. (2021). Unemployment Rate. https://www.stats.govt.nz/indicators/unemploymentrate

Tamers, S. L., Streit, J., Pana-Cryan, R., Ray, T., Syron, L., Flynn, M. A., Castillo, D., Roth, G., Geraci, C., Guerin, R., Schulte, P., Henn, S., Chang, C-C., Felknor, S., Howard, J. (2020). Envisioning the future of work to safeguard the safety, health, and well-being of the workforce: A perspective from the CDC's National Institute for Occupational Safety and Health American Journal of Industrial Medicine, 63(12), 1065-1094. https://doi.org/10.1002/ajim.23183

Taylor, M. K. (2018). Xennials: a microgeneration in the workplace. Industrial and Commercial Training, 50(3), 136-147. https://doi.org/10.1108/ICT-08-2017-0065 
van der Lippe, T., Lippényi, Z. (2020). Beyond Formal Access: Organizational Context, Working From Home, and Work-Family Conflict of Men and Women in European Workplaces. Social Indicators Research, 151, 383-402. https://doi.org/10.1007/s11205-018-1993-1

Wang, B., Liu, Y., Qian, J., \& Parker, S. K. (2020). Achieving Effective Remote Working During the COVID-19 Pandemic: A Work Design Perspective. Applied Psychology, 70(1), 16-59. https://doi.org/10.1111/apps.12290

WHO. (2020). Coronavirus disease (COVID-19) pandemic. https://www.who.int/emergencies/diseases/novel-coronavirus-2019

Williams, F. (2001). In and beyond New Labour: towards a new political ethics of care. Critical Social Policy, 21(4), 467-493. https://doi.org/10.1177/026101830102100405

Wood, S. (2005). Spanning the Generation Gap in the Workplace. JournalAWWA (American Water Works Association), 97(5), 86-89. https://doi.org/10.1002/j.1551$\underline{8833.2005 . t b 10888 . \mathrm{x}}$

World Economic Forum. (2021). Preparing for the Future of Work. https://www.weforum.org/projects/future-of-work 